Case Reports in
Gastroenterology
Case Rep Gastroenterol 2020;14:367-372

DOI: $10.1159 / 000508583$

Published online: July 28,2020
(C) 2020 The Author(s)

Published by S. Karger AG, Basel www.karger.com/crg

This article is licensed under the Creative Commons Attribution-NonCommercial 4.0 International License (CC BY-NC) (http://www.karger.com/Services/OpenAccessLicense). Usage and distribution for commercial purposes requires written permission.

\title{
Tumor Lysis Syndrome after Combination Therapy of Nivolumab and Sorafenib in a Woman with Advanced Hepatocellular Carcinoma
}

\author{
Tsai-Hung Yen $^{a}$ Chung-Hsin Chang ${ }^{b}$ Sz-luan Shiu ${ }^{b-d}$ \\ aDivision of Allergy, Immunology and Rheumatology, Department of Internal Medicine, \\ Taichung Veterans General Hospital, Taichung, Taiwan, ROC; ${ }^{\text {bDivision of }}$ \\ Gastroenterology and Hepatology, Department of Internal Medicine, Taichung Veterans \\ General Hospital, Taichung, Taiwan, ROC; 'Department of Critical Care Medicine, Taichung \\ Veterans General Hospital, Taichung, Taiwan, ROC; ${ }^{d}$ Evidence-Based Practice and \\ Policymaking Committee, Taichung Veterans General Hospital, Taichung, Taiwan, ROC
}

\section{Keywords}

Tumor lysis syndrome $\cdot$ Nivolumab · Sorafenib · Advanced hepatocellular carcinoma

\begin{abstract}
Tumor lysis syndrome (TLS) is a life-threatening emergency that usually develops in rapidly proliferating hematologic malignancies or advanced solid tumor following cytotoxic chemotherapy or therapeutic interventions. TLS is especially rare in patients with hepatocellular carcinoma (HCC). Therefore, we present a case of a female patient with newly diagnosed advanced HCC who developed TLS and hepatic failure after receiving combination therapy of nivolumab and sorafenib. To our knowledge, this is the first case of TLS in a patient with advanced HCC owing to combination therapy of nivolumab and sorafenib. We also reviewed the literature and summarized the characteristics of TLS in patients with advanced HCC receiving various therapeutic interventions. The overall mortality rate was $63 \%$ and regarding the management, transarterial chemoembolization (TACE) was the most common etiology. TACE-related TLS developed more rapidly than sorafenib-related TLS. Furthermore, the efficacy and safety of combination therapy of nivolumab and sorafenib should be further evaluated, and TLS should still be a concern, especially in patients with large tumor burden.




\section{Case Reports in Gastroenterology}

Case Rep Gastroenterol 2020;14:367-372

DOI: 10.1159/000508583

(c) 2020 The Author(s). Published by S. Karger AG, Basel www.karger.com/crg

Yen et al.: TLS after Nivolumab and Sorafenib in a Woman with Advanced HCC

\section{Introduction}

Tumor lysis syndrome (TLS) is a life-threatening catastrophe characterized by hyperuricemia, hyperkalemia, hyperphosphatemia, and hypocalcemia [1, 2]. These metabolic imbalances can result in acute kidney injury, cardiac arrhythmia, neurological sequela, and finally death owing to multiple organ failure. TLS usually occurs in patients with rapidly proliferating hematologic malignancies or advanced solid tumor following cytotoxic chemotherapy or therapeutic intervention [2,3]. TLS is extremely rare in patients with hepatocellular carcinoma (HCC), and has been reported infrequently in circumstances of medical conditions, such as spontaneity without preceding chemotherapy [4], therapeutic transarterial chemoembolization (TACE) [5], and initiation with sorafenib [6]. The epidemiology, optimal treatment, and prognosis in this patient population is not clear. We present a case of TLS after combination therapy of nivolumab and sorafenib in a woman with advanced HCC.

\section{Case Presentation}

A 43-year-old woman presented to the outpatient clinic with the chief complaint of insidious-onset, persistent, moderately severe, and poorly localized abdominal pain for more than a month. She also mentioned the rapid onset of yellowish skin color, tea-colored urine, and swelling in bilateral legs 1 week prior to admission. She had a history of chronic hepatitis B infection and did not follow up regularly. The physical examination at admission revealed acute ill-looking appearance as well as icteric sclera, skin, and mucus membrane. Abdominal examination showed palpable liver and spleen contour with shifting dullness while no muscle guarding or rebounding pain was found upon palpation. The rest of the physical examination was unremarkable.

Laboratory examination revealed a total leukocyte count of 9,060 cells $/ \mu \mathrm{L}$, hemoglobin concentration of $12.1 \mathrm{~g} / \mathrm{dL}$, and platelet count of 243,000/ $\mu \mathrm{L}$. Her ALT was $127 \mathrm{U} / \mathrm{L}, \mathrm{AST} 268$ U/L, ALP $468 \mathrm{U} / \mathrm{L}$, serum total bilirubin $2.9 \mathrm{mg} / \mathrm{dL}$ (direct fraction $1.1 \mathrm{mg} / \mathrm{dL}$ ), albumin 3.2 $\mathrm{g} / \mathrm{dL}$, creatinine $76.9 \mu \mathrm{mol} / \mathrm{L}$, lactate dehydrogenase $537 \mathrm{U} / \mathrm{L}$, alpha-fetoprotein 317,333 $\mathrm{IU} / \mathrm{mL}$, INR 1.26, and activated partial thromboplastin time of $26.2 \mathrm{~s}$ on initial presentation. In addition, serum markers were positive for hepatitis B surface antigen and hepatitis B envelope antigen while hepatitis B virus DNA was $1.67 \times 10^{6} \mathrm{IU} / \mathrm{mL}$. Abdominal sonography showed multiple hepatic masses over bilateral lobes, hepatosplenomegaly, and massive ascites indicating hepatic malignancy and liver cirrhosis. Triple-phase CT of the abdomen revealed infiltrative HCC bilaterally with lymphadenopathy over the retroperitoneum, main portal vein thrombosis, and bone metastasis at the third lumbar spine (Fig. 1a-c). According to the Barcelona Clinic Liver Cancer (BCLC) classification the patient was diagnosed with advanced-stage HCC and received entecavir upon admission. Due to the rapid progression of tumor burden we administered nivolumab $200 \mathrm{mg}(2.1 \mathrm{mg} /$ day) intravenously on the 8th day of hospitalization and prescribed sorafenib $200 \mathrm{mg}$ daily as combination therapy from the 9th day of hospitalization. On the 15th day sorafenib was discontinued due to deterioration of serum total bilirubin to $5.8 \mathrm{mg} / \mathrm{dL}$, and on the 18th day her ALT was 1,303 U/L, AST 6,220 U/L, ALP $752 \mathrm{U} / \mathrm{L}$, serum total bilirubin $16.9 \mathrm{mg} / \mathrm{dL}$, INR 1.88, ammonia $54 \mu \mathrm{mol} / \mathrm{L}$, creatinine $236 \mu \mathrm{mol} / \mathrm{L}$, potassium $6.1 \mathrm{mmol} / \mathrm{L}$, phosphate $7.4 \mathrm{mmol} / \mathrm{L}$, calcium $2.1 \mathrm{mmol} / \mathrm{L}$, and uric acid 1,118.2 $\mu \mathrm{mol} / \mathrm{L}$. Decompensated hepatic failure associated with TLS was diagnosed according to clinical and laboratory criteria defined by Cairo et al. [7]. After establishing TLS, we prescribed $1.5 \mathrm{mg}$ of rasburicase twice daily from the 18th day, and the patient was admitted to 


\section{Case Reports in Gastroenterology}

Case Rep Gastroenterol 2020;14:367-372

DOI: $10.1159 / 000508583$

(c) 2020 The Author(s). Published by S. Karger AG, Basel www.karger.com/crg

Yen et al.: TLS after Nivolumab and Sorafenib in a Woman with Advanced HCC

the intensive care unit with vigorous hydration to maintain urine output. We also corrected electrolyte abnormalities and monitored vital signs closely. However, acute kidney injury with anuria developed along with hepatic encephalopathy despite intensive care, and the patient expired on the 21st day of hospitalization.

\section{Discussion}

TLS in advanced HCC is rare but challenging in clinical management with a total of 16 cases, including our case, reported in the literature (see the online Supplementary file; for all online suppl. material, see www.karger.com/doi/10.1159/000508583). The mean patient age at admission was approximately 57 years with a male predominance $(87.5 \%)$ (online suppl. Table 1). Most of the patients belonged to hepatitis B virus-related HCC and had large tumor burden with a mean maximal diameter of HCC of $12.7 \mathrm{~cm}$ and mean alpha-fetoprotein of $62,838 \mathrm{IU} / \mathrm{mL}$. The overall mortality rate was $63 \%$, and the mean onset of TLS following treatments was 5 days. Regarding the management, TACE was performed in $63 \%$ of the patients while sorafenib, thalidomide, and combined therapy of nivolumab plus sorafenib were performed in 25, 6, and $6 \%$ of the patients, respectively. TACE-related TLS developed more rapidly with the mean onset time being only 1.1 days compared to sorafenib-related TLS which usually developed after 7 days. In our presented case, TLS developed 9 days after combining sorafenib to nivolumab therapy.

HCC is the second most common cause of cancer-related death worldwide (http:// globocan.iarc.fr/old/FactSheets/cancers/liver-new.asp) and approximately one third of the patients have advanced-stage HCC with an average survival period of 6-12 months [8]. For patients with advanced HCC, both systemic therapies [9] and therapeutic TACE [10] were recommended as standard treatments worldwide. First-line therapies including sorafenib and lenvatinib have been shown to be effective individually as well as regorafenib as second-line therapy after failure of sorafenib. Nivolumab has also been approved as second-line therapy by the FDA, while cabozantinib was demonstrated to be superior to placebo in second or third line. However, most of the patients with advanced HCC treated initially by sorafenib stopped sorafenib eventually due to either disease progression [11] or intolerance to adverse effects [12] with median overall survival prolonged for only 2.8 months. The unsatisfactory therapeutic response to sorafenib and slow tumor proliferation of HCC may contribute simultaneously to the rare incidence of sorafenib-induced TLS. Few cases of sorafenib-induced TLS have been reported in the literature [6] with characteristics of increasing tumor burden such as multifocal tumors, extrahepatic metastasis, and high alpha-fetoprotein. Sorafenib-induced TLS usually developed 7-30 days following sorafenib treatment.

On the other hand, nivolumab, a fully human immunoglobulin G4 monoclonal antibody that disrupts PD-1 immune checkpoint signaling, was reported to have $20 \%$ of grade $3 / 4$ treatment-related adverse events in patients with advanced HCC after receiving sorafenib but none of them developed TLS, liver failure, or treatment-related death [13]. To the best of our knowledge, nivolumab-induced TLS has never been reported in the literature despite comprehensive searching. Therefore, we reported the first case of TLS developed after combination of nivolumab and sorafenib in a woman with advanced HCC which raised concern about the safety issue after a combination of systemic therapies with different mechanisms in advanced HCC. The concept of combining first- or second-line therapies in advanced HCC has not yet been mentioned in the guidelines, and only one case report has been published regarding the synergistic efficacy of transarterial radioembolization, sorafenib, and nivolumab [14]. 


\section{Case Reports in Gastroenterology}

\begin{tabular}{l|l}
\hline Case Rep Gastroenterol 2020;14:367-372 \\
\hline DOI: 10.1159/000508583 & $\begin{array}{l}\text { @ 2020 The Author(s). Published by S. Karger AG, Basel } \\
\text { www.karger.com/crg }\end{array}$ \\
\hline
\end{tabular}

Yen et al.: TLS after Nivolumab and Sorafenib in a Woman with Advanced HCC

Treatment response due to immunotherapy is often delayed and improved only in overall survival. This slow response might be due to a phenomenon known as antigen spreading proposed by Gulley et al. [15]. As the identification of cancer-specific antigens by immune system continues, another process by which cancer cells die and present an antigen that generates an immune response is recognized as immunogenic cell death. Systemic therapies [16], which enhance either antigen spreading or immunogenic cell death, might be the backbone for nivolumab-based regimens. However, the interacting mechanism between these regimens is still unelucidated. Further studies to determine the efficacy of combination therapy for patients with advanced HCC and the potential risk of developing TLS following the treatment are needed.

To our knowledge, this is the first case of TLS after combination therapy of nivolumab and sorafenib in a woman with advanced HCC. It emphasizes the need for individualized treatment to achieve a beneficial clinical outcome in patients with advanced-stage HCC with large tumor burden and the concern for monitoring adverse events like TLS.

\section{Acknowledgments}

The authors wish to thank the Evidence-based Practice and Policymaking Committee, Taichung Veterans General Hospital (Taichung, Taiwan, ROC).

\section{Statement of Ethics}

Written informed consent was obtained from the patient and her family for the publication of this case report and any accompanying images.

\section{Conflict of Interest Statement}

The authors have no conflicts of interest to declare in relation to this article.

\section{Funding Sources}

The authors did not receive any financial compensation for this article.

\section{Author Contributions}

T.-H.Y. and C.-H.C. designed the meta-analysis. T.-H.Y. and S.-I.S. contributed to data acquisition and drafted the article. T.-H.Y., S.-I.S., and C.-H.C. contributed to data analysis and interpretation. All authors performed critical revision of the manuscript and approved the final draft of the article. 


\section{Case Reports in Gastroenterology}

\begin{tabular}{l|l}
\hline DOI: 10.1159/000508583 & (c) 2020 The Author(s). Published by S. Karger AG, Basel \\
\hline
\end{tabular} www.karger.com/crg

Yen et al.: TLS after Nivolumab and Sorafenib in a Woman with Advanced HCC

\section{References}

1 Calvo Villas JM. Tumour lysis syndrome. Med Clin (Barc). 2019 May;152(10):397-404.

2 Howard SC, Jones DP, Pui CH. The tumor lysis syndrome. N Engl J Med. 2011 May;364(19):1844-54.

3 Cairo MS, Coiffier B, Reiter A, Younes A; TLS Expert Panel. Recommendations for the evaluation of risk and prophylaxis of tumour lysis syndrome (TLS) in adults and children with malignant diseases: an expert TLS panel consensus. Br J Haematol. 2010 May;149(4):578-86.

4 Agarwala R, Batta A, Suryadevera V, Kumar V, Sharma V, Rana SS. Spontaneous tumour lysis syndrome in hepatocellular carcinoma presenting with hypocalcemic tetany: an unusual case and systematic literature review. Clin Res Hepatol Gastroenterol. 2017 Jun;41(3):e29-31.

5 Hsieh PM, Hung KC, Chen YS. Tumor lysis syndrome after transarterial chemoembolization of hepatocellular carcinoma: case reports and literature review. World J Gastroenterol. 2009 Oct;15(37):4726-8.

6 Imam SZ, Zahid MF, Maqbool MA. Sorafenib-induced tumor lysis syndrome in a patient with metastatic hepatocellular carcinoma. Hematol Oncol Stem Cell Ther. 2018 Apr;S1658-3876(18)30029-3.; Epub ahead of print.

7 Davidson MB, Thakkar S, Hix JK, Bhandarkar ND, Wong A, Schreiber MJ. Pathophysiology, clinical consequences, and treatment of tumor lysis syndrome. Am J Med. 2004 Apr;116(8):546-54.

8 Giannini EG, Farinati F, Ciccarese F, Pecorelli A, Rapaccini GL, Di Marco M, et al.; Italian Liver Cancer (ITA.LI.CA) group. Prognosis of untreated hepatocellular carcinoma. Hepatology. 2015 Jan;61(1):184-90.

9 Heimbach JK, Kulik LM, Finn RS, Sirlin CB, Abecassis MM, Roberts LR, et al. AASLD guidelines for the treatment of hepatocellular carcinoma. Hepatology. 2018 Jan;67(1):358-80.

10 Zhao Y, Cai G, Zhou L, Liu L, Qi X, Bai M, et al. Transarterial chemoembolization in hepatocellular carcinoma with vascular invasion or extrahepatic metastasis: A systematic review. Asia Pac J Clin Oncol. 2013 Dec;9(4):357-64.

11 Llovet JM, Ricci S, Mazzaferro V, Hilgard P, Gane E, Blanc JF, et al.; SHARP Investigators Study Group. Sorafenib in advanced hepatocellular carcinoma. N Engl J Med. 2008 Jul;359(4):378-90.

12 Cheng AL, Kang YK, Chen Z, Tsao CJ, Qin S, Kim JS, et al. Efficacy and safety of sorafenib in patients in the Asia-Pacific region with advanced hepatocellular carcinoma: a phase III randomised, double-blind, placebocontrolled trial. Lancet Oncol. 2009 Jan;10(1):25-34.

13 El-Khoueiry AB, Sangro B, Yau T, Crocenzi TS, Kudo M, Hsu C, et al. Nivolumab in patients with advanced hepatocellular carcinoma (CheckMate 040): an open-label, non-comparative, phase 1/2 dose escalation and expansion trial. Lancet. 2017 Jun;389(10088):2492-502.

14 Adcock CS, Puneky LV, Campbell GS. Favorable response of metastatic hepatocellular carcinoma to treatment with trans-arterial radioembolization followed by sorafenib and nivolumab. Cureus. 2019 Feb;11(2):e4083.

15 Gulley JL, Madan RA, Pachynski R, Mulders P, Sheikh NA, Trager J, et al. Role of antigen spread and distinctive characteristics of immunotherapy in cancer treatment. J Natl Cancer Inst. 2017 Apr;109(4). https://doi.org/10.1093/jnci/djw261.

16 Kwilas AR, Donahue RN, Tsang KY, Hodge JW. Immune consequences of tyrosine kinase inhibitors that synergize with cancer immunotherapy. Cancer Cell Microenviron. 2015;2(1):e677. 
Case Reports in Gastroenterology

\begin{tabular}{l|l}
\hline Case Rep Gastroenterol 2020;14:367-372 \\
\hline DOI: 10.1159/000508583 & $\begin{array}{l}\text { @ 2020 The Author(s). Published by S. Karger AG, Basel } \\
\text { www.karger.com/crg }\end{array}$ \\
\hline
\end{tabular}

Yen et al.: TLS after Nivolumab and Sorafenib in a Woman with Advanced HCC
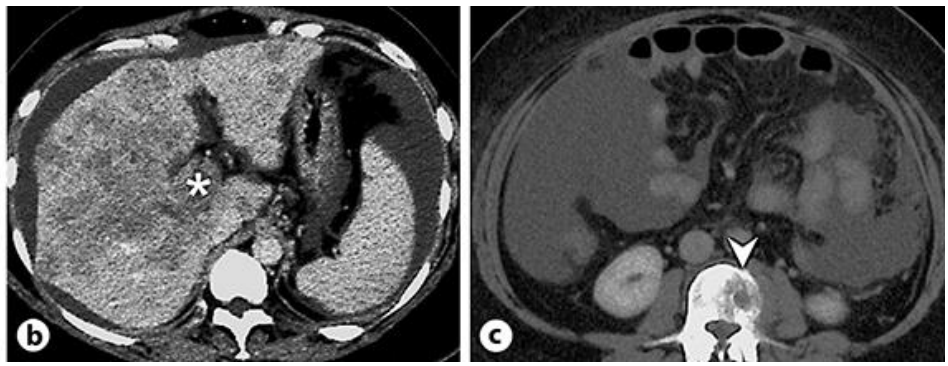

Fig. 1. Triple-phase CT of the abdomen revealed infiltrative HCC bilaterally with an early enhancement pattern at the arterial phase (a), early washout pattern at the portal phase (b), main portal vein thrombosis (asterisk), and bone metastasis with osteolytic characteristics (arrowhead) at the third lumbar spine (c). 